\title{
VARIACIONES GreENBERG: APOGEO Y DEBACLE DE UN CRÍTICO DE ARTE
}

\author{
Nicholas Rauschenberg ${ }^{1}$
}

\begin{abstract}
Resumen: Partiendo del texto clásico Vanguardia y kitsch, nos proponemos analizar la obra del crítico norteamericano Clement Greenberg. Después de la intervención del Estado norteamericano en el arte entre 1935 y 1943 (los WTA), Clement Greenberg surge como uno de los principales críticos que buscaron unificar el "arte elevado" de ese país. Para tanto, el crítico norteamericano busca justificar el nivel artístico de esa vanguardia acercando esa producción a las vanguardias europeas, especialmente el cubismo. Veremos los problemas de Greenberg al forjar una "historicidad inmanente" a las obras de arte para justificar una posible convergencia de las vanguardias europeas en el nuevo contexto de la vanguardia norteamericana: el "expresionismo abstracto". Greenberg, con ayuda del MoMA y del Estado norteamericano buscó fomentar una "pintura a la americana", una vanguardia conocida como escuela de Nueva York. Buscamos analizar el contexto en que se forjó esa tendencia artificiosamente unificada y cómo el pop art emerge como una crítica performática de ese contexto. Más que vanagloriarse de sus métodos técnicos, el pop art busca subvertir el contexto de recepción del arte que hasta entonces era expectante del "arte serio y elevado" defendido por Greenberg.
\end{abstract}

Palabras Clave: Clement Greenberg. Expresionismo abstracto. Kitsch. Vanguardia. Pop art.

El mismo discurso sobre el kitsch comienza a convertirse en kitsch al sucumbir a la dialéctica histórica de la que emergió su objeto. (ADORNO, 2011, p. 828).

Según Abraham Moles (1990), el adjetivo kitsch surge en el sur de Alemania aproximadamente en 1860 . Con influencia del dialecto yiddish, el verbo alemán kitschen significaba, por un lado, quebrantar los granos de cereales o legumbres: frangollar. Por otro, también significaba hacer algo deprisa y mal, y, en particular, "hacer muebles nuevos con viejos" (MOLES,

${ }^{1}$ Professor do Departamento de Sociologia da Universidade de Buenos Aires, Buenos Aires - Argentina.
(D) https://orcid.org/0000-0002-1779-0622 Email: nicholasrauschenberg@yahoo.com.br

http://dx.doi.org/10.1590/0101-3173.2019.v42n3.07.p119 
1990, p. 9). El verbo verkitschen quería decir "hacer pasar gato por liebre". Verkitschen - verbo que hoy en día ya no se usa - cargaba un significado ético-peyorativo: una negación de lo auténtico. Llevado al campo del arte, kitsch significa un deterioro o una estafa a sabiendas de "la víctima". Ya en el campo del arte, Hermann Broch dirá que "la esencia del kitsch consiste en la substitución de la categoría ética con la categoría estética; impone al artista la obligación de realizar, no un 'buen trabajo' sino un trabajo 'agradable': lo que más importa es el efecto" (BROCH, 1970, p. 9). Sin embargo, esto no significa decir que todo "arte auténtico" se rehúsa a producir efectos. El uso del adjetivo kitsch se refiere más al ámbito de recepción del arte que el de su producción. La idea de "autenticidad del arte" está en juego en un mundo del arte que ya tiene discursos - muchos de ellos conflictivos - orientados a validar ciertas tendencias estéticas reconocidas. Sin duda lo kitsch puede referirse a aspectos muy amplios y específicos a la vez, y la fuerza de su significación es performativa: es un adjetivo descalificador, indica que cierta obra de arte tiene algo de inauténtico, de falso, de trampa, de imitación, de retroceso estético, de simplificación con la finalidad de provocar "efectos agradables" posiblemente pensando en el mercado. El término kitsch no tiene, por lo tanto, un significado absoluto: es un calificativo negativo pero que se usa en cierto contexto. Nos interesa pensar la noción de kitsch en la obra de Clement Greenberg. Para eso, buscaremos desarrollar cinco fragmentos: (I) la noción de vanguardia como oposición al kitsch; (II) el juicio estético y su inevitable "historicidad inmanente"; (III) el modernismo pictórico europeo del cual parte esa historicidad en términos empíricos; (IV) el expresionismo abstracto norteamericano pensado aquí como un contexto de aplicación de la historicidad del modernismo pictórico; y finalmente $(\mathrm{V})$ un poco del contexto de la guerra fría y la intervención estatal norteamericana en el mundo del arte en el momento en que se consolidaba del pop art. ¿Es posible afirmar que la vanguardia defendida por Greenberg se había vuelto kitsch?

\section{(I) VANGUARDIA Y KITSCH}

Para el crítico norteamericano Clement Greenberg (1909-1994), parte de la sociedad burguesa occidental buscó una instancia de autonomía artística las vanguardias - para producir formas de arte que rompieran con la ineludible "función representativa" del arte en favor de una diversidad de abstracciones pictóricas. La vanguardia conformaría "una consciencia superior de la historia [...] el surgimiento de un nuevo tipo de crítica de la sociedad, la crítica 
histórica” (GREENBERG, 2006a, p. 24). Fue en su búsqueda de lo absoluto que la vanguardia, así como la poesía y otras formas de arte, llegaron al "arte abstracto" o "no objetivo". "El contenido ha de disolverse tan completamente en la forma que la obra plástica o literaria no puede ser reducida en su totalidad o parcialmente a nada que no sea ella misma." (GREENBERG, 2006a, p. 26). La vanguardia está en movimiento en sí misma: sus mejores artistas son artistas para artistas, y compiten entre ellos. Eso eleva admirablemente el nivel de la producción artística. Para Greenberg, sin embargo, donde hay una vanguardia artística hay siempre una retaguardia. Esa retaguardia está impregnada de lo kitsch: revistas, anuncios, ficciones baratas, películas de Hollywood etc. "El kitsch, que usa como materia de base los simulacros envilecidos y academizados de la cultura genuina, ve con buenos ojos y cultiva esa insensibilidad, que es la fuente de sus ganancias." (GREENBERG, 2006a, p. 31). Tanto para Greenberg como para Hermann Broch, la oposición entre arte auténtico y el arte kitsch tiene que ver con "valores". Para justificar los valores del arte auténtico, Broch acusa al kitsch de ser un claro y deshonesto retroceso. Y esos valores, según Greenberg, deben ser buscados en las transformaciones técnicas de las obras de vanguardia en el sentido de una "evolución". No se trata para el autor estadounidense de elegir meramente entre lo más nuevo y lo más viejo, sino estar al tanto de las actualizaciones técnicas de la historia del gran arte, especialmente en una pérdida de la necesidad de la "representación mimética" en favor del arte abstracto. El kitsch es un problema para Greenberg porque tiene escala mundial - sincrónico, por lo tanto - gracias a la internacionalización de la revolución industrial. En la antigua Unión Soviética - si tenemos en cuenta que Greenberg escribe Kitsch y vanguardia en 1939 - los ciudadanos aprendían a apreciar el arte elevado, se incentivaba el cine de vanguardia, pero sin embargo las masas preferían consumir las películas de Hollywood. ¿Cuál sería entonces para Greenberg el "valor" del arte auténtico? Como ejemplo, Greenberg compara una obra realista de Repin y otra cubista de Picasso. Es evidente que para un campesino ruso de esa época es mucho más accesible entender el cuadro de Repin, mientras que para entender el de Picasso hace falta conocer como mínimo contextos de historia del arte. Sin embargo, Greenberg busca enaltecer los valores artísticos que el espectador culto encuentra en Picasso porque son obtenidos en un segundo momento: como resultado de la reflexión sobre la "impresión inmediata dejada por los valores plásticos” (GREENBERG, 2006a, p. 37). Podríamos afirmar que Greenberg no deja de justificar cierta ontología del arte. Como Heidegger, que afirma que 
ante todo la obra de arte tiene un carácter "cósico", Greenberg sugiere que la obra de Picasso invita a pensar las formas en un sentido inmanente.

Recordemos que para Heidegger "el origen de la obra de arte es el arte" (2014, p. 60). El arte se realiza en la obra de arte. Pero la duda sigue: ¿Cómo sabemos que estamos ante una obra de arte auténtica? En Heidegger, lo auténtico se vincula a una necesaria idea de verdad. Así, "uno de los modos como acontece la verdad es el ser-obra de la obra. Estableciendo un mundo y haciendo la tierra, la obra es el sostener aquella lucha en que se conquista la desocultación del ente en totalidad, la verdad." (HEIDEGGER, 2014, p. 77). Heidegger asocia el ente a lo familiar, a aquello que es "de confianza" y seguro. Sin embargo, al pensar la obra de arte como un ente es necesario buscar la verdad: hay "un permanente ocultarse en el doble aspecto del negarse y el disimularse” (HEIDEGGER, 2014, p. 76). La verdad en el arte aparece oculta, por eso hay que desocultarla: revelarla. En la obra de arte "está en operación el acontecimiento de la verdad” (HEIDEGGER, 2014, p. 80). Esa operación es para Heidegger una lucha primordial entre alumbramiento y ocultación. Eso significa que la verdad no puede existir previamente como venida de las estrellas y alojada mágicamente en el ente, sino que es algo que el sujeto debe reconstruir desde su vivencia a través del lenguaje. "En la obra el ser-creado está expresamente creado dentro de lo creado de manera que resalta el producto. Si es así, tenemos que poder experimentar el ser creado de la obra." (HEIDEGGER, 2014, p. 87). La realidad de la obra de arte no se agota en su "ser-creatura" porque el encuentro entre obra y sujeto donde se da parte sustancial de la lucha entre alumbramiento y ocultación es un acontecimiento. El acontecimiento del ser-creación de la obra "no sigue simplemente vibrando en la obra, sino que lo que tiene de acontecimiento el que la obra sea esta obra, proyecta la obra en torno y constantemente la tiene proyectada" (HEIDEGGER, 2014, p. 88). Teniendo como ejemplo el cuadro de Van Gogh Par de botas, pintado en 1886, Heidegger explica que la pintura de las botas no sólo se refieren al "ser útil”, sino que además esa representación aspira a una totalidad pero que tiene necesariamente una apertura: "El mundo y la tierra en su juego recíproco, logra la desocultación.” (HEIDEGGER, 2014, p. 78). "En el zapato vibra la tácita llamada de la tierra, su reposado ofrendar el trigo que madura y su enigmático rehusarse en el yermo campo en baldío del invierno." (HEIDEGGER, 2014, p. 53).

El clásico texto de Greenberg Vanguardia y kitsch rozaba asumir un rasgo elitista con su aspecto crítico del arte de masas. Por un lado, defendía 
una perspectiva que sostenía que las obras de arte auténticas producidas por la vanguardia dependían de la capacidad del individuo para entenderla y rescatar lo universalmente significativo. Aquí lo aproximamos a la actitud de la apertura del ser del ente heideggeriano, la desocultación en la experiencia estética, una búsqueda por la verdad del arte en el arte. En esa búsqueda Greenberg nos llevará a una teoría inmanente de la historia del arte. El arte buscará justificarse a través de la "sutil exposición de las principales líneas históricas de la vanguardia y del modo como todas ellas conspiraron para estrechar y elevar el arte a la expresión de un absoluto" (CLARK, 1997, p. 218). Por otro lado, el rasgo elitista de Vanguardia y kitsch revelaba el lugar contradictorio de la vanguardia como perteneciente a la propia burguesía. Esa vanguardia concibe un arte inferior - sea kitsch o la industria cultural - "producido para las masas por las clases dominantes del capitalismo avanzado como parte de su vil manejo de la escena democrática” en su intento de simular que las masas realmente gobiernan (CLARK, 1997, p. 218). Había existido una identidad burguesa y una cultura burguesa clásica del siglo XIX. Pero cuando esa burguesía creó las formas de la sociedad de masas para atrincherarse en el poder creó también una pseudocultura destruyendo sus propias formas de "cultura" que habían madurado a lo largo de siglos con el dominio absolutista y aristocrático y la oposición que la propia burguesía les ejercía. "El modernismo aparece entonces como un modo de arte burgués en la ausencia de una burguesía, o, más precisamente, como arte aristocrática en la época en que la burguesía abre mano de sus pretensiones aristocráticas" (CLARK, 1997, p. 220), por lo menos en lo que se refiere al arte. Greenberg buscará rescatar una actitud aristocrática para criticar el poder burgués desde el margen, pero ese margen busca ocupar la cima por querer detener los valores y los sentidos del arte. Ese es el núcleo dialéctico del pensamiento de Greenberg.

Apoyándose en Marx, Greenberg sostendrá que el arte hace parte de un proyecto revolucionario. Esta expectativa normativista de un arte vanguardista que abre un horizonte emancipador aproxima Greenberg a Theodor W. Adorno. El contexto de surgimiento de las ideas de ambos es prácticamente el mismo: ambos entienden que el kitsch se vincula a la industria cultural y saben del peligro demagógico del kitsch aliado al fascismo. Ya no se trata de una ingenua división entre arte bueno - o técnicamente superior - y un arte malo o meramente comercial para las masas. Entra en juego la distorsión de esa división ante la amenaza del fascismo y las democracias de masas. Las elites en los regímenes totalitarios abrieron mano de universalizar sus preferencias estéticas. Había que hacerle creer a las masas ilusionadas que la literatura y 
el arte que les gustaba y entendían eran el único arte y la única literatura auténticos y que se debía suprimir cualquier otro. Para Adorno, "lo kitsch parodia a la catarsis" (2005, p. 316). Pensar el kitsch no es sólo una cuestión de arte superior o inferior, de elite o popular. Greenberg abre su célebre texto afirmando que tanto el kitsch como el arte elevado coexisten y busca atribuirle valor al "arte elevado". Para Adorno, sin embargo, "lo kitsch no es, como quisiera la fe en la cultura, un mero producto de desecho del arte, surgido mediante una acomodación cultural, sino que espera en el arte a que llegue la ocasión de emerger desde el arte" (ADORNO, 2005, p. 316). Si Greenberg vincula categóricamente el kitsch al "arte inferior", para Adorno es difícil juzgar dónde empieza y dónde termina lo kitsch; es como si lo kitsch fuera un veneno que está mezclado con todo tipo de arte. Cuanto más el arte quiere alejarse de él, más él parece retornar triunfante. Segregar el kitsch "es uno de los esfuerzos desesperados del arte de hoy" (ADORNO, 2005, p. 316). Pero Adorno no pierde, como Greenberg, la ilusión de que el verdadero arte está plagado de buenas intenciones. "El arte respeta a las masas al presentarse ante ellas como lo que ellas podrían ser en vez de adaptarse a ellas en su figura degradada." (ADORNO, 2005, p. 316).

\section{(II) Problemas en torno al juicio estético: ¿ڤistoricidad inmanente?}

En escritos posteriores Greenberg buscará justificar su idea de juicio del gusto, acercándose, con algunas importantes diferencias, al concepto de gusto kantiano. Greenberg sostiene que "los juicios son dados y contenidos en la experiencia inmediata del arte. Coinciden con ella; no son algo a que se llegue posteriormente a través de la reflexión o pensamiento" (GREENBERG, 1997e, p. 117). Los juicios estéticos son involuntarios, es decir, no se puede decidir si a uno le gusta o no una obra de arte. Los juicios estéticos son inmediatos, intuitivos, no deliberados e involuntarios, es decir, "no dan lugar a la aplicación de estándares, criterios, reglas y preceptos" (GREENBERG, 1997e, p. 117). Para Greenberg no es posible separar el momento del juicio del momento de placer. El juicio y el placer se refieren mutuamente, son sincrónicos. El placer - o el displacer - está en el juicio. El juicio genera placer y el placer hace posible el juicio. Greenberg cree que el efecto de placer del arte consiste en una "sensación" de "conocimiento exaltado" [exalted cognitiveness] - "exaltado porque esa sensación trasciende el conocimiento como tal" (GREENBERG, 1999, p. 9). Las obras supremas exaltan el conocimiento. El placer de la experiencia estética es el placer de la consciencia. El estado de 
exaltación del conocimiento o de la consciencia es el valor estético o la calidad. $\mathrm{El}$ arte inferior - la experiencia estética inferior - se muestra a sí mismo como insuficiente al conocimiento. Pero todo arte, toda experiencia estética, ya sea buena o mala, promete o intima una promesa de exaltación. "Y es sólo la intuición estética - el gusto - que puede decir hasta qué punto se mantiene la promesa." (GREENBERG, 1999, p. 9). Esa intuición es un a priori de cada sujeto. Algunos la tienen más que otros. Sin embargo, ya no se estaría hablando con Kant de un sujeto trascendental, sino de un sujeto abstracto con especial sensibilidad para el arte, o por lo menos con la capacidad de ampliarla.

"En el carácter involuntario del juicio estético reside una libertad preciosa: la libertad de ser sorprendido, dominado, de tener sus expectativas contrariadas, la libertad de ser inconsecuente y de que a uno le guste cualquier cosa desde que sea bueno. La libertad, en suma, de dejar que el arte permanezca abierto." (GREENBERG, 1997e, p. 119). Pese a que la intuición estética es involuntaria, es posible, sin embargo, determinar el foco de la atención que se direcciona a una determinada obra de arte. Es imposible, claro, demonstrar que una obra de arte es superior a otra. Greenberg ofrece un ejemplo: los versos de Eliot y Watson sobre la llegada de la primavera en abril. Aunque se consideren algunos parámetros estilísticos - que en opinión del crítico tienden a favorecer a Eliot - no se puede afirmar de modo absoluto su superioridad. Por otro lado, al atenerse a criterios técnicos, se corre el riesgo de desarrollar un prejuicio de modo a evaluar una obra antes de verla. Se perdería la experiencia subjetiva de enfrentarse a la apertura del ser de la obra y su "desocultación", para mencionar a Heidegger. ¿Cómo determinar el criterio o valor de la calidad de una obra entonces? En la Estética de lo sublime - parte central de la Crítica del juicio - Kant sostendrá que "el gusto es la capacidad de enjuiciar a priori la comunicabilidad de los sentimientos que están enlazados con una representación dada (sin la mediación de un concepto)" (KANT, 2003, \$40, p. 261).

Para Kant (2003, \$40, p. 260),

el gusto puede llamarse sensus communis con más derecho que el sano entendimiento; y que el discernimiento estético, antes que el intelectual, puede portar el nombre de sentido comunitario, si se desea emplear la palabra "sentido" a propósito de un efecto de la mera reflexión sobre el ánimo: pues entonces se entiende por sentido el sentimiento de placer. Podría incluso definirse al gusto mediante la capacidad de enjuiciamiento de aquello que hace comunicable universalmente nuestro sentimiento en una representación dada sin la mediación de un concepto. 
Greenberg se apoya en ese argumento de la comunicabilidad para sugerir que los sujetos interesados en arte pueden intercambiar sus puntos de vista de modo a desarrollarlos, mejorarlos y acumularlos. Los juicios estéticos, por lo tanto, no pueden ser probados o ni siquiera cuestionados, pero pueden ser discutidos. Es posible, por lo tanto, "influenciar la atención del interlocutor mostrándole los aspectos sobre los cuales recayó su intuición buscando una nueva visita a la obra” (PASSOS, 2013, p. 54). Eso le permitiría al interlocutor vivenciar en un nuevo nivel de percepción los potenciales inmanentes de la obra. Ese potencial dialógico de los veredictos críticos - que muchas veces operan como verdaderas "justificaciones" - basados en una abstracción del acto de "percibir" o "vivenciar" una obra de arte forman un "consenso".

En lenguaje kantiano, el juicio estético según Greenberg sería un "juicio reflexionante", es decir, parte de algo específico hacia algo general e indeterminado. Greenberg sostendrá que es el juicio estético el que se encarga de elaborar con su experiencia ante las obras criterios concretos para que los juicios no sean "puramente subjetivos". De este modo, Greenberg sostiene que "los veredictos de aquellos que más se preocupan con el arte y más le dedican atención terminan a lo largo del tiempo formando un consenso" (GREENBERG, 1997e, p. 117). Además, "el arte tiene su historia como un mero fenómeno y también como calidad” (GREENBERG, 1997e, p. 119). Greenberg está interesado en la construcción de conceptos a posteriori para justificar que hay arte superior y arte inferior. "Lo que forma el consenso del gusto es el mejor gusto." (PASSOS, 2013, p. 57). El mejor gusto es aquel que se desarrolla bajo la presión del mejor arte. Para Greenberg, por tanto, el mejor gusto y el mejor arte son indisolubles. Y es la función del crítico contribuir para revelar el valor de las obras.

Greenberg buscará sostener la construcción del objeto de la experiencia estética a partir conocimiento empírico-histórico del arte: busca en las obras una historicidad inmanente. Su objeto será el arte moderno como una percepción de autonomía del arte, algo que llamará arte "puro". Como explica Arthur Danto, "para Greenberg cada pintura modernista tendría que ser entonces una crítica de la pintura pura: pintura desde la cual uno estaría capacitado para deducir los principios peculiares de ese arte en tanto tal" (2014, p. 90). Si subrayamos el interés - la finalidad - historicista presente en las críticas de Greenberg, podremos concordar con Rosalind Krauss cuando dice que la crítica autodenominada modernista es inocente. Primero, porque esa crítica modernista se rehúsa a ver la temporalidad que nunca se cansa de 
invocar - "toda la historia de la pintura desde Manet" - "como esa armadura perspectivista sobre la que ella estructura el arte en cuestión (y sobre la que ese arte tendió cada vez más a estructurarse)" (KRAUSS, 1997, p. 169). En segundo lugar, esa crítica modernista da por sentado que su historia es "objetiva", por encima de la "ideología". Y tercero, esa crítica no acepta autocrítica y es prescriptiva.

\section{(III) GREENBERG Y LA RECONSTRUCCIÓN DEL MODERNISMO PICTÓRICO}

Si seguimos el planteo de Peter Bürger sobre "cómo identificar la vanguardia”, por así decirlo, podemos suponer que Greenberg creyó haber encontrado en el "expresionismo abstracto" norteamericano - décadas de 1940-1950 - la vanguardia de su propio tiempo. A partir de ese momento, "el arte alcanza el estadio de autocrítica" que permitiría la "comprensión objetiva” de las épocas anteriores en el desarrollo artístico, para usar la terminología de Bürger (1987, p. 62). Las categorías generales de las obras de arte identificadas por los desarrollos vanguardistas que tiene en cuenta Greenberg proporcionaron un verdadero abandono de la "representación" mimética. Greenberg propone retomar el breve texto de Lessing, Laocoonte o sobre las fronteras de la pintura y la poesía (1766), donde el autor alemán busca semejanzas y diferencias entre la poesía y la pintura. En los tiempos de Lessing - cuando aún no existía la fotografía y la pintura se dedicaba a "representar" mimética y realísticamente - la poesía como escritura y sonido poético parecía ser más abstracta. Para Lessing, la pintura tenía una espacialidad y proyectaba imágenes concretas que la alejaban de las construcciones más abiertas y sugestivas de la poesía. La pintura "representaba" a cuerpos, lugares y cosas, mientras que la poesía representaba acciones, sensaciones imágenes imprecisas. Greenberg cree que es necesario invertir esa expectativa funcional de la pintura, y para eso propone aproximarla al paradigma de la música, especialmente la música moderna, en oposición al predominio "literario-representativo". El interés por la música llevó a la vanguardia a considerarla "un método de arte" y no como un tipo de efecto. "La ventaja de la música residía sobre todo en el hecho de que ella es un arte abstracto." (GREENBERG, 1997a, p. 53).

Para eso Greenberg sugiere una reconstrucción del lugar de las artes - especialmente la pintura - desde el romanticismo - última gran tendencia directamente resultante de la sociedad burguesa - hasta su momento presente. A mediados del siglo XIX el romanticismo ya mostraba claros señales de 
agotamiento. Según Greenberg, el nuevo ímpetu de las artes, antes que confirmar a la lógica social burguesa, vendría más bien a negarla, a rechazarla. Ya no se propondría una nueva sociedad, sino que el lugar de la creación sería el margen, es decir, el lugar de la vanguardia pasaría a ser la bohemia: "El santuario del arte en medio al capitalismo." (GREENBERG, 1997a, p. 49). La vanguardia asume la función de encontrar formas culturales nuevas y adecuadas para la expresión de la sociedad distanciándose de las "divisiones ideológicas". Según Greenberg, la vanguardia - hija y negación del romanticismo - pasa a encarnar el "instinto de autopreservación del arte" (GREENBERG, 1997a, p. 50). Y librarse de las luchas ideológicas era condición de posibilidad para el desarrollo del arte: le permitía a la vanguardia un distanciamiento crítico en relación al predominio del contenido de las obras. Esa distancia, por lo tanto, pone el énfasis en la forma, dejando el contenido de las obras en segundo plano. Junto a eso se suma una mayor autonomización de las distintas disciplinas artísticas. Para Greenberg, esa especialización fue una reacción contra el dominio de la literatura, modo de arte que donde predominaría "el tema" y no tanto la forma. En su noción de "modernismo", Greenberg considera que "cada arte tuvo que determinar, mediante sus propias operaciones y obras, sus propios efectos exclusivos” (GREENBERG, 1997b, p. 102). El área de competencia única y propia de cada arte coincidía con todo lo que era único en la naturaleza de sus medios. Cada arte podría llegar a tornarse "pura" y en esa "pureza" encontraría la garantía de sus estándares de calidad, así como su independencia. Para Greenberg, "pureza” significa "autodefinición”, y la misión de la autocrítica en las artes se convirtió en la necesidad de una autodefinición radical. El arte realista, naturalista, había disimulado los medios usando el arte para ocultar el arte. El modernismo, a su vez, usó el arte para llamarle la atención al propio arte.

La ruptura "inicial" con el "estándar literario" en el campo de la pintura la realiza Gustave Courbet (1819-1877) que, según Greenberg, al huir del "espíritu hacia la materia" reduciendo su arte a los datos sensoriales inmediatos, se transformó "en el primer verdadero pintor de vanguardia” (GREENBERG, 1997a, p. 50). El crítico norteamericano destaca la nueva "planaridad" que surge en las telas de Courbet. El impresionismo, siguiendo los pasos de ese "objetivismo material" de Courbet, buscaba emular la imparcialidad de la ciencia para buscar una esencia de la pintura y de la experiencia visual. En ese sentido, "la pintura impresionista se convierte más en un ejercicio de vibraciones de color que en representación de la naturaleza" (GREENBERG, 1997a, p. 51). Siguiendo a Édouard Manet (1832-1883), "los impresionistas 
repudiaron las subcapas y los barnices para no dejar ninguna duda de que los colores usados eran de pintura salida de tubos y tarros" (GREENBERG, 1997b, p. 102). El impresionismo llevó tan lejos la reproducción fiel de la naturaleza que la pintura figurativa perdió el parámetro de representación. Retomando la bidimensionalidad perdida desde el Renascimiento, el nuevo positivismo impresionista enfatizaba lo material en la tela. "Las sensaciones de una tercera dimensión no son dadas por la visión como tal, sino por asociaciones adquiridas con la experiencia del movimiento y del tacto." (GREENBERG, 1997c, p. 63). Lo que conforma una visión en un sentido literal no son más que colores. A pesar de la fuerte perspectiva atmosférica no más tridimensional y excesivamente mimética - el énfasis está puesto en el plano y en la naturaleza física de la tela y de la pintura aplicada sobre esta con su consecuente relieve, ya anunciando una ruptura con lo representativo y liso de la fotografía. Para respetar la "planaridad" bruta de la superficie, Paul Cézanne (1839-1906) fragmentó los objetos que pintaba en una multiplicidad de planos que eran dispuestos lo más paralelo posible en relación a la superficie de la tela. En el cuadro de Cézanne Manzanas y naranjas, Greenberg destaca en la frágil línea azul que "separa el contorno de una manzana de su masa sigue habiendo algo indescriptiblemente vivo e inesperado" (GREENBERG, 2006b, p. 52). Las distorsiones del dibujo de Cézanne provocadas por la exactitud extremadamente literal de su visión, así como por una preocupación por lo que sería la representación "en profundidad" a la forma bidimensional de la tela, "contribuyeron a su espontáneo énfasis en el plano desprovisto de profundidad” (GREENBERG, 2006b, p. 55). Cézanne logró entonces una transformación del método impresionista, que hasta entonces basado en el "registro de las variaciones de color puramente ópticas", buscando reflejar las alteraciones de la profundidad y la dirección de los planos a través - más que en atención a - de las variaciones de color (GREENBERG, 2006b, p. 55).

Las tensiones entre la moldura del cuadro y las formas dentro de la tela también estaban presentes en Vincent Van Gogh (1853-1890) y Paul Gauguin (1848-1903). Buscando una materialidad propia con los modos de aplicación, el pigmento por veces aplicado de manera tan suave que la tela quedaba visible o era acumulado como una pasta que sobresalía el relieve de la pintura. Esa era la "paradoja" de Van Gogh y Gauguin: querían, por un lado, liberar a la pintura del meterialismo "mimético" que aún se resistía en el impresionismo, pero por otro, lo hacían recurriendo a una intensa materialidad en la tela (GREENBERG, 1997c, p. 64). Ya a comienzos del siglo XX, los fovistas hicieron cuadros estructurados en color "chapado" e intenso, que 
era arbitraria en cualquier sentido figurativo y relativamente disociado de su contorno. La destrucción del espacio pictórico realista fue llevada a cabo a través de la parodia que fue el cubismo. El pintor cubista eliminaba el color porque - queriendo o no - estaba parodiando, con el objetivo de destruir, los métodos académicos para la obtención de volumen, que son el sombreado y la perspectiva, y que como tales poco tienen que ver con el color. El cubista usó esos métodos para fragmentar la tela en una multiplicidad de sutiles planos recesivos que parecen desplazarse y desaparecer en profundidades infinitas $y$, sin embargo, insisten en retornar a la superficie de la tela. Al mirar una pintura cubista observamos, al mismo tiempo, "el nacimiento y la muerte del espacio pictórico tridimensional” (GREENBERG, 1997a, p. 57). Para Greenberg, el cubismo fue algo así como "una contrarrevolución". Pintores como Picasso, Braque y Gris hicieron cuadros en que la identidad de los objetos se había desfigurado, aunque después "dieron media vuelta y volvieron a la representación” (GREENBERG, 1997a, p. 64). Más tarde, no obstante, otros artistas aceptaron la lógica cubista y se tornaron abstraccionistas importantes "resignándose a lo no representativo y a la inviolabilidad de la superficie plana" [flatness] (GREENBERG, 1997a, p. 64). Ya con Piet Mondrian (1872-1944), los cruces de líneas negras y los rectángulos de color parecen insuficientes para constituir un cuadro. Esos cruces no hacen más que imponer la forma de la moldura como "norma reguladora" (GREENBERG, 1997b, p. 105). El arte de Mondrian se revela "demasiado disciplinado", demasiado volcada hacia la tradición y la convención: su absoluta abstracción es más conservadora en su color y en la sumisión a la moldura que las últimas pinturas de Manet (GREENBERG, 1997b, p. 106):

Mondrian partió de la fase del cubismo analítico a la que habían llegado Picasso y Braque hacia 1912, cuando sus cubos se transformaron en pequeńos rectángulos y semicírculos planos que se confundían cada vez más con el fondo y el cuadro elaborado mediante pequeñas pinceladas inconfundibles de un color uniforme - una especie de puntillismo - que enfatizaba la superficie al liberarla. (GREENBERG, 2006c, p. 47).

Greenberg se vale, por lo tanto, de esta reconstrucción histórica y parcial para caracterizar su noción de arte moderno para defender la continuidad histórica del arte "de vanguardia". Esa búsqueda necesariamente "evolutiva" - quizá "continuista" - tuvo como uno de sus ejes la "planaridad". "El modernismo jamás pretendió una ruptura con el pasado." (GREENBERG, 1997b, p. 107). Sin embargo, por más que Greenberg haya hecho hincapié 
en la "planaridad" [flatness] y en el abandono de la representación mimética, eso no significa que hay una evolución a un arte mejor en términos absolutos, sino apenas "más avanzada" en términos históricos. La continuidad permite establecer diálogos y rupturas en distintos contextos, sea para pensar una rehabilitación de un autor a partir de nuevas prácticas o para criticar de modo inmanente un determinado conjunto de obras.

\section{(IV) GREENBERG Y EL EXPRESIONISMO ABSTRACTO NORTEAMERICANO}

La justificación "artística", por así decirlo, para el término "expresionismo abstracto" se debe a que la mayoría de los pintores norteamericanos de esa época tenían como referencia el "expresionismo alemán, ruso, judaico, desprendiéndose del arte abstracto cubista tardío" (GREENBERG, 1997d, p. 77). Sin embargo, Greenberg sentencia que todos se espejaron de alguna manera en la pintura francesa a partir de la cual crearon su estilo, con rupturas y continuidades. También Picasso estaba muy presente en el espíritu de esos pintores, especialmente el Picasso de los años 1930. Surgía entonces un primer problema: el de cómo ampliar la ilusión tan rígidamente demarcada de profundidad superficial [shallow depth] en que Picasso había trabajado en sus cuadros más osados. La premisa teórica de Greenberg es que, ante un pasado irresistible como Picasso, Van Gogh y Mondrian, un joven artista suele buscar un precedente alternativo. "Para producir arte significativo es necesario en general asimilar el arte importante del período anterior, o de los períodos anteriores." (GREENBERG, 1997d, p. 76). El "arte avanzado" persiste en la medida en que pone a prueba la aptitud de la sociedad para el "arte elevado". La búsqueda por constituir un arte avanzado logra su objetivo probando los límites de las formas y géneros heredados, así como los artistas del propio contexto. Es lo que hicieron "los impresionistas, los post-impresionistas, los fovistas, los cubistas y Mondrian” (GREENBERG, 1997d, p. 92). Greenberg buscará de este modo interpretar las obras de los expresionistas de su país teniendo en cuenta rupturas y continuidades con pintores y estilos del pasado, especialmente las vanguardias europeas.

Arshile Gorky (1904-1948) "se sometió a Miró para distanciarse de Picasso” (GREENBERG, 1997d, p. 78). Gorky descubrió su propio camino "para atenuar la tensión del espacio picassoide" y aprendió a hacer con que las formas planas floten en un fondo móvil e indefinido (GREENBERG, 1997d, p. 78). Aunque Greenberg declare que Gorky es uno de los mejores 
pintores que tuvo Estados Unidos, le reprocha que siguió siendo un cubista tardío y que, además, tenía un gusto muy francés, un pintor de caballete ortodoxo, un virtuoso de las líneas, pero no un colorista. Otro importante pintor comentado por Greenberg es Willem de Kooning (1904-1997), quien se aproxima de Gorky por la predominancia del dibujo en detrimento de la coloración. "Los contornos desencarnados de las composiciones de figuras desnudas de Michelangelo y Rubens invaden sus telas abstractas, pero sus rastros mezclados de blanco, gris y negro por los cuales se insiere una ilusión de superficial de profundidad evocan de modo persistente el Picasso de los años 1930.” (GREENBERG, 1997d, p. 79). Así como Picasso, Willem de Kooning no abandona la figura humana y para eso se vale de las líneas y los sombreados. Otro pintor, Hans Hofmann (1880-1966), empezó a pintar a partir de Matisse y todos los fovistas, pero también siguió a Kandinsky y a Picasso: Hofmann "tiende a yuxtaponer colores intensos, vibrantes, cuyo calor y luminosidad uniformes tornan los contrastes de valor disonantes, más que de lo que los obscurecen" (GREENBERG, 1997d, p. 80). Adolph Gottlieb (1903-1974) y Robert Motherwell (1915-1991) permanecen más cercanos al cubismo tardío, aunque no pertenezcan a él directamente. Aunque haga una simplificada composición casi geométrica cercana al estilo de Picasso y Matisse, y prefiera contrastes de color claros y simples dentro de una gama bastante restringida, Motherwell es menos un cubista tardío que Willem de Kooning. Sus primeros collages, "de un cubismo explosivo" análogo al de de Konning adquirieron una unidad profunda y original y, entre 1947 y 1951, pintó varios cuadros bastante grandes que están, según Greenberg, entre las obras primas del expresionismo abstracto.

Pero para Greenberg, el más importante pintor del expresionismo abstracto fue Jackson Pollock (1912-1956). Greenberg lo consideraba un "cubista tardío" hasta 1946, y la excelencia precoz de su arte podría ser pensada como "la realización de cosas que Picasso dejara apenas en estado de promesa en su período 1932-1940" (GREENBERG, 1997d, p. 82). En un texto de 1947, Greenberg lo acerca al postcubismo de Miró e insinúa además que Pollock también se inspira en "Kandinsky y el Surrealismo" (GREENBERG, 1986, p. 166). Aunque no sea el punto fuerte construir con el color, Pollock tiene un instinto para arriesgadas oposiciones entre claro y oscuro. Pollock trabajaba telas all over con enmarañados y manchas de pintura metálica que abría y tiraba entrelazándolas con distintas intensidades y dibujos de cierta regularidad pero de cierto modo espontáneo y no figurativo. Para Greenberg, el "cubismo analítico" estuvo siempre presente en el espíritu de Pollock. Su 
giro al all over se debe a su deseo de controlar cierta "oscilación entre una superficie física enfatizada y la sugestión de profundidad tan lúcida, tensa y equilibrada como Picasso y Braque habían controlado un movimiento algo similar con los planos facetados y el puntillismo de color de sus telas cubistas de 1909-1913" (GREENBERG, 1997d, p. 83).

Greenberg menciona además otros pintores como Mark Tobey (18901976), el primero a alcanzar la composición all over; Franz Kline (1910-1962), en cuya primera exposición en 1951 pintó fondos blancos con una destacada imagen caligráfica en negro; y Mark Rothko (1903-1970), al que Greenberg veía como postimpresionista y cuyas "grandes telas verticales con color incandecentes y su sensualidad audaciosa están entre las más significativas joyas del expresionismo abstracto" (GREENBERG, 1997d, p. 89). Menciona también a Barnett Newman (1905-1970) y sus fajas verticales de colores contrastantes sobre fondos calientes y lisos. Greenberg sabe que Newman no es propiamente un "expresionista", pero busca incorporarlo a "la escuela". Sin embargo, Newman publica en 1964 un texto acusando a Greenberg de forjar un contenido metafísico a una supuesta unidad de pintores como si todos tuvieran un a priori formal a partir del cual orientar su trabajo. En su búsqueda por nuevos procedimientos e imágenes, los "pintores americanos" buscan

el caos de la pura fantasía y del sentimiento sin tener en cuenta una contrapartida física, visual o matemática conocida y extraen de ese caos de emoción imágenes que le dan realidad a esos intangibles. No hay ningún esfuerzo para llegar a lo fantástico a través de lo real, o a lo abstracto a través de lo real. Al contrario, el esfuerzo busca extraer de lo no real, del caos del éxtasis, algo que evoque la memoria de la emoción de un momento experimentado de total realidad. (NEWMAN, 1997, p. 153).

Esa artificialidad continuista y unificadora del expresionismo abstracto presente en la crítica de Greenberg se hace más evidente si la contrastamos con los textos del crítico Harold Rosenberg (1994). Si Greenberg buscaba una derivación sistemática desde la historicidad de la vanguardia como "continuidad" y evolución del "arte avanzado", Rosenberg sostendrá que la vanguardia es necesariamente una ruptura, y ese sería el caso de la pintura norte americana que Greenberg llama "expresionismo". Influenciado más por autores existencialistas, Rosenberg buscará otra matriz interpretativa para las obras, rompiendo con el empirismo de lo material - como la "planaridad", las texturas, etc. - en que se apoya Greenberg. El action painting - y ya no el all over - será considerado por Rosenberg como la clave de la especificidad de 
buena parte de la pintura norteamericana que Greenberg quiere acomodar a su explicación en términos de genealogía histórica. Si para Greenberg en la planaridad se plasmaba una técnica expresiva sofisticada, como si el pintor supiera de inicio lo que será el producto final de su obra, Rosenberg valorará el proceso de pintura, considerándolo un "evento". Pintar es una acción que presupone un acontecimiento y un encuentro. La ruptura vanguardista de la action painting residía en la total eliminación del tema identificable, del dibujo, la composición, rompiendo inclusive con modos de uso del color y de las texturas. Según Rosenberg, no era raro considerar que el lienzo pasaba a ser considerado una arena para favorecer el carácter de happening del proceso de pintura. El action painting se transformó en un importante y accesible lenguaje artístico desde mediados de los años 1930 cuando el propósito era "una educación de las masas" para el arte, lo que produjo estilos de pintura de descontentamiento social. Es decir, el action painting, además de ser incorporado como técnica de grandes nombres de la pintura, no necesariamente está planteado como un procedimiento de composición elitista como sugiere Greenberg al abogar por el "arte elevado". "Con el sentimiento de crisis desplazado hacia las alegrías del profesionalismo, sólo le restó transformar angustia y espontaneidad en rótulos." (ROSENBERG, 1997 , p. 160). Rosenberg (1997, p. 158) quiere hacer que se reconozca que el gran arte norteamericano de las galerías "falsifica la relación existente entre arte y sociedad". Rosenberg acusa a Greenberg de trabajar para coleccionistas y experts - además de la política cultural del Estado - que sólo se preocupan con la especulación en el "mercado de las obras primas": "En esta parodia de historia del arte, el artista desaparece y las pinturas brotan unas de otras sin la ayuda de cualquier otro principio generador que no sea 'una ley del desarrollo' que el crítico tiene en sus manos.” (ROSENBERG, 1997, p. 159).

En el breve ensayo Abstracción postpictórica, de 1964, Greenberg (1997f) busca analizar nuevas tendencias del expresionismo norteamericano teniendo en cuenta la noción de action painting. El texto buscaba mostrar un poco del contexto de las obras de John Ferren, Sam Francis y Helen Frankenthaler, entre otros, como una segunda generación del expresionismo norteamericano. Lo que llama la atención de ese ensayo es el uso de la palabra "manierismo" para indicar una masificación del action painting como mera convención:

El toque de la calle Diez (Tenth Street touch, en alusión a la East Tenth Street, en Nueva York) que se alastró como una plaga por la pintura abstracta en la década de 1950. La marca dejada por un pincel o espátula cargados cuando es suficientemente larga se fragmenta en tiras, ondulaciones y 
gotas de pintura que crean variaciones de claros y oscuros mediante las cuales las pinceladas yuxtapuestas se funden sin contrastes abruptos. [...] A partir de esas variaciones o gradaciones cerradas de claro y oscuro se constituyó la pintura expresionista abstracta típica, con su típica densidad de modulaciones y su aspecto saturado, agitado. (GREENBERG, 1997f, p. 112-113).

Vale recordar que tanto Greenberg como Rosenberg rechazaron el $p o p$ art que surgía con fuerza a principio de los años 1960. Para Rosenberg eran imitaciones idiotas de ítems de la comunicación de masas, un resurgir del ilusionismo, una búsqueda farsante por la angustia del cotidiano materializado en sus productos industriales. No hay ni proceso ni acontecimiento y el arte pop necesita "manuales de uso" para hacerse entender (ROSENBERG, 1997, p. 162). Para Greenberg, a su vez, hay una reacción contra el expresionismo abstracto: una viene de la segunda generación y busca una sofisticada desmasificación del action painting. La otra es el pop art. Sin embargo, por más que sea divertida Greenberg no considera que el pop art sea realmente original. "El arte pop desafía el gusto solo superficialmente. Hasta ahora (con excepción tal vez de Jasper Johns) el pop art equivale a un nuevo episodio en la historia del gusto, pero no a un nuevo episodio auténticamente nuevo en la evolución del arte contemporáneo.” (GREENBERG, 1997f, p. 115).

\section{(V) El RETORNO DE LO KITSCH: DE LA GUERRA FRÍA AL POP ART}

Hay una dialéctica, anunciada por el joven Adorno ya en 1932, de la que Greenberg no puede escapar: "El mismo discurso sobre el kitsch comienza a convertirse en kitsch al sucumbir a la dialéctica histórica de la que emergió su objeto." (ADORNO, 2011, p. 828). Si a fines de los años 1930 era necesario denunciar el kitsch como "engaño de las masas" y "arte inauténtico", poco más de veinte años después el "expresionismo abstracto" empezó a sucumbir como movimiento de vanguardia para cederle a contrapelo su lugar de hegemonía al pop art. ¿Cómo se dio esa "transición", por así decirlo? El propio Greenberg anticipaba una banalización del action painting y la dificultad de encontrar una segunda generación tan revolucionaria como la primera. El contexto de surgimiento era diferente. De los Works Project Administration (WTA) del New Deal de principio de los 30, pasamos al absoluto dominio del MoMA (Museo de Arte Moderna de Nueva York) controlado por la familia Rockefeller y el departamento de Estado norteamericano para hacer del "expresionismo" su gran 
arte nacional en las principales exposiciones del mundo. A eso debe sumarse una creciente elitización de las galerías y la constitución de un complejo "mundo del arte" (BECKER, 2008). El uso del arte abstracto, es decir, su resignificación como "arma en la Guerra Fría" (COCKCROFT, 1985) abrió la posibilidad de un resurgimiento absolutamente irónico de la condición del arte como liberación de lo kitsch y búsqueda de superioridad técnica y artística. Un primer ejemplo de esa inversión irónica es que la Partisan Rewiew - revista conocida por su perfil troskista - así como algunas otras publicaciones especializadas en arte, recibían ayuda económica de la CIA para promover el "expresionismo abstracto" (LASCH, 1968, p. 353). Otro claro ejemplo de esa irónica inversión de sentido político de los artistas, sus obras y la intención de los críticos en el contexto de la guerra fría es la intervención del gobierno de EEUU en el evento "100 American Artists”, en junio de 1956. Dicha intervención consistió en la censura de algunos artistas que simpatizaban con el socialismo. Ese evento fue organizado por la Federación Americana de Artes - con sede en Nueva York - para la USIA (United States Information Agency). En solidaridad con los artistas que serían excluidos, el consejo directivo de la federación amenazó con suspender el evento si no se respetaba la resolución de 1954 en la que se establecía que "el arte debe ser juzgada por sus méritos como obra de arte y no por la visión social y política de sus artistas" (COCKCROFT, 1985, p. 152).

Greenberg es muy categórico cuando afirma que no hubiese sido posible a los artistas norteamericanos empezar una carrera alineada con su tiempo y desarrollar técnicas y estilos "no provincianos" sin la ayuda del WTA Art Project, activado de 1935 hasta 1943 (GREENBERG, 1997d). En el contexto del New Deal, el Works Project Administration (WTA) era un organismo público dedicado a dar empleo a los artistas. Casi todos los pintores del así llamado expresionismo abstracto trabajaron para la WTA. Pero la participación del Estado norteamericano en el campo del arte no termina con el WTA. Es sintomático de esa intervención que Greenberg recuerde, en una entrevista a Ann Hindry, ya en 1993, que el Consejo Internacional del MoMA había organizado una exposición itinerante de arte norteamericana por el Pacífico. Greenberg fue enviado a Japón por el departamento de Estado. El MoMA es un instituto privado perteneciente a la familia Rockeffeler y en esa época estaba comprometido junto al gobierno en promover el arte de vanguardia norteamericano como un arte de "expresión libre", contra los estereotipos del "realismo socialista", en el contexto del fervoroso anticomunismo de la Guerra Fría (COCKCROFT, 1985). Un ejemplo del poder del MoMA fue la participación de EEUU entre 1954 y 1962 en la Bienal de Venecia: el pabellón que representaba el arte norteamericano no sólo 
era exclusivamente organizado por el MoMA y, así, dedicado al expresionismo hegemónico, sino que también era la única colección privada, en contraste con las colecciones parcial o totalmente estatales de las otras delegaciones (SHAPIRO et al., 1985, p. 192).

El "expresionismo abstracto" como movimiento estético excedió los límites deseables que necesitaría una vanguardia, si entendemos que ésta busca una ruptura, una crítica o una anticipación. Greenberg sostuvo el expresionismo desde una idea de continuidad sobre todo con el cubismo. En todo caso, la idea de ruptura como "estilo americano" era mucho más fuerte en críticos como Harold Rosenberg. Y no debe haber existido nunca una "vanguardia" artística que se haya convertido en punta de lanza de una guerra cultural como lo fue la guerra fría. Esa contradicción aparecía en un mercado de arte saturado de expectativas estéticas "apolíticas" que en realidad, por un lado, querían significar un "arte libre", pero, por otro, sus principales nombres eran usados políticamente por el Estado norteamericano con apoyo de las principales corporaciones - como la familia Rockeffeler - en contradicción con las visiones políticas de sus propios pintores. Ante la paradoja de un arte libre y virtuoso que derivaba en una libertad políticamente artificiosa y el "desinterés" que quería sostener, hubo una ruptura vanguardista: el $p o p$ art, una forma de ironía contra esa vanguardia "continuista" y aferrada al stablishment del arte oficial del Estado. Sin embargo, esa ruptura no significó un retorno idílico a las vanguardias europeas, como soñaba Greenberg en relación al modernismo pictórico. La condición hegemónica de potencia mundial de Estados Unidos y su arte oficial empezaba a ser ironizada en obras de artistas norteamericanos como Jasper Johns: las obras La bandera (The Flag) (de 1955), que mostraba una bandera de su país, y Tres banderas (Three flags) (de 1958), constituida por la imagen de tres banderas del mismo país pero de tamaños distintos teniendo el centro de la bandera como referencia. El arte ya no tenía su "valor" por un complejo intercambio de tradiciones vanguardistas con sus sofisticadas técnicas y un abandono de la "representación mimética". Al cambiar la naturaleza objetual del arte, el pop art desplazaba el idealizado y exigente contexto de producción para ironizar el contexto de recepción de las obras de arte. El expresionismo abstracto tenía un contexto de recepción claro: su mundo de críticos, marchands, coleccionistas, museos y el propio gobierno, etc. Pero los creadores de las obras se tomaban muy "en serio" ese circuito de evaluadores. El pop art buscó romper esa "seriedad" como "valor", por lo menos en un primer momento, hasta pasar a ser el gran arte de las galerías encabezado por Andy Warhol y su "fábrica". 
Bourdieu - quien trabajó el campo de la literatura francesa de fines del siglo XIX - podría estar de acuerdo en que el expresionismo abstracto tenía fe - ilusio - en las reglas del campo, en nuestro caso el mundo del arte y sus disputas por reconocimientos de artistas, coleccionadores, museos etc. (DANTO, 2012). Y esa ilusión, según Greenberg, estaba determinada por la calidad, por la derivación en términos de lenguajes compartidos, pretensiones estéticas con innovación técnica, etc. Sin embargo, en la vanguardia el capital político - sobre todo aquél vinculado al poder del stablishment - no es tan preciado como el capital simbólico - que en el caso de la vanguardia serían las técnicas innovadoras y la recusa a la representación mimética en favor de la expresividad, el valor de buscar un lenguaje auténtico, no "kitsch". El pop art, a su vez, valora el kitsch como una manera de romper el purismo en el arte y la ilusión de una "obra auténtica", ya que el serialismo y la repetición son parte de la estrategia subversiva del pop art. Es decir, el pop art pone el foco de la obra en el contexto de recepción y multiplicación de significados a partir de un significante archiconocido. El capital económico del expresionismo estaba sobrevalorado si tenemos en cuenta el modelo economicista de Bourdieu, para quien la vanguardia, al proponer rupturas, abre mano del reconocimiento económico en favor del capital simbólico. Sin embargo, el pop art luego seguiría la lógica económica de las galerías y museos. El pop art buscaba o encontró su validación - justamente en anular esa brecha cualitativa "del gusto" defendida por Greenberg. El capital específico del pop art era "hacerse conocer con algo conocido", literalmente desplazando el significado. El artista también debería ser conocido y vincular su marca a su obra. Si para Bourdieu la vanguardia busca renunciar al capital económico para valorar su capital simbólico, el pop art buscabará, sobre todo con Andy Warhol invertir esa ecuación (RAUSCHENBERG, 2019).

\section{CONSIDERACIONES FINALES}

Más que determinar - o por lo menos sugerir parcialmente - las diferencias entre el así llamado expresionismo abstracto y el pop art, lo que buscamos a lo largo del texto fue analizar el pensamiento de Clement Greenberg como un defensor de la vanguardia pictórica de Nueva York de la primera mitad del siglo XX. Vimos que en su defensa del arte de vanguardia Greenberg incurre en cuatro errores. El primero se refiere al "historicismo inmanente" del arte que entiende que las obras de arte "modernas" componen una unidad históricamente determinable vinculada a sus técnicas, especialmente lo que 
Greenberg llama "planaridad". La construcción material de esa planaridad daría por sentado un progresivo abandono de la necesidad de representación o ilustración, en términos realistas - de las obras de arte. Esa liberación del arte hacia "lo abstrato", sobre todo teniendo en cuenta que la fotografía asumiría la función de realismo en la imagen, permite a los pintores un despliegue técnico jamás visto. Sin embargo, Greenberg busca asociar esa liberación - que tiene necesariamente un múltiple carácter de ruptura - a una "continuidad vanguardista", como si el "espíritu de la vanguardia", por así decirlo, fuera pasible de unificación, ignorando, por ejemplo, la infinidad de manifiestos y movimientos artísticos de la época de las vanguardias, por así decirlo. El segundo error de Greenberg es creer que el modo compositivo de las obras del expresionismo abstracto está en continuidad con el cubismo (y algunas otras tendencias y estilos europeos), como quedó problematizado en el debate entre Greenberg y Rosenberg. El action painting buscaba valorar el procedimiento como expresividad y acontecimiento, sin importar a principio el resultado final, mientras que en el cubismo - y en buena parte de lo que Greenberg llamó modernismo pictórico - predomina una composición parcial y previamente elaborada. El tercer error se refiere a la ingenua pretensión de clasificar dicho arte moderno - sobre todo en el conturbado contexto norteamericano, New Deal, Guerra Fría etc. - como "puro" y autónomo, como si lo único relevante tanto para el contexto de producción como para el contexto de recepción fuera el arte técnicamente valorable - el "arte elevado", "avanzado". El pop art surge como reacción a las elevadas pretensiones artísticas de dicha vanguardia, pero sobre todo gracias a la conversión del expresionismo a ser el gran arte norteamericano con ayuda del gobierno y las corporaciones institucionalizadas en el MoMA. Finalmente, el cuarto y último error se refiere a la relación misma entre vanguardia y lo kitsch. Buscamos problematizar la noción de kitsch de Greenberg enfrentándola a la de Adorno. Si Greenberg busca asociar lo kitsch al engaño y a la cultura inferior - posición que en términos generales Adorno estaría de acuerdo -, Adorno no ignora el uso performativo del kitsch como una característica del mundo del arte: pese a advertir el carácter paródico de catarsis que tiene el kitsch, Adorno sostiene que únicamente la fe en la cultura no puede ser una modalidad preventiva contra el kitsch. El kitsch emerge desde el arte y como motor histórico de la superación del propio arte. 
RAUSCHENBERG, N. The Greenberg variations: apogee and debacle of an art critic. Trans/form/ação, Marília, v. 42, n. 3, p. 119-142, Jul./Set., 2019.

ABSTRACT: Starting from the classic text Avant-garde and kitsch, we propose to analyze the work of the North American critic Clement Greenberg. After the US state intervention in the arts between 1935 and 1943 (the WTA), Clement Greenberg emerged as one of the main critics who sought to unify the "high art" of that country. The critic attempted to justify the artistic level of the American avant-garde by bringing it closer to the European avant-gardes, especially Cubism. We will see Greenberg's problems in forging an "immanent historicity" of works of art in order to justify a possible convergence of the European avant-garde in the new context of an American avant-garde of "abstract expressionism". Greenberg, with the help of the MoMA and the American government, sought to promote an "American painting", a vanguard known as the New York school. We seek to analyze the context in which this artificially unified tendency was forged, and to analyze how pop art emerged as a performance critique of that context. More than boasting of its technical methods, pop art sought to subvert the context of the reception of art that until then expected the "serious and high art" defended by Greenberg.

Kerwords: Clement Greenberg. Abstract expressionism. Kitsch. Avant-garde. Pop art.

\section{REFERENCIAS}

ADORNO, T. W. Escritos musicales. In: Obras completas, V. 18. Madrid: Akal, 2011. . Teoría estética. In: Obras completas, V. 6. Madrid: Akal, 2005.

BECKER, H. Mundos del arte: sociología del trabajo artístico. Bernal: Universidad de Quilmes, 2008.

BOURDIEU, P. As regras da arte. São Paulo: Campanhía das Letras, 1996.

BROCH, H. Kitsch, vanguardia y el arte por el arte. Barcelona: Tusquets, 1970.

BÜRGER, P. Teoría de la vanguardia. Barcelona: Península, 1987.

CLARK, T. J. A teoria da arte de Clement Greenberg. In: FERREIRA, G.; MELLO, C. C. (org.). Clement Greenberg e o debate crítico. Rio de Janeiro: Jorge Zahar, 1997. p. 211-232.

COCKCROFT, E. Abstract expressionism, weapon of the Cold War. In: FRASCINA, F. (org.). Pollock and After. London and New York: Routledge, 1985. p. 147-154.

DANTO, A. O mundo da arte. In: DUARTE, R. O belo autônomo: textos clássicos de estética. Belo Horizonte: Autêntica y Crisálida, 2012.

. Después del fin del arte: el arte contemporáneo y el linde de la historia. Buenos Aires: Paidós, 2014.

GREENBERG, C. Vanguardia y kitsch. In: La pintura moderna y otros ensayos. Madrid: Siruela, 2006a. p. 23-44. 
. Cézanne y la unidad del arte moderno. In: La pintura moderna y otros ensayos. Madrid: Siruela, 2006b. p. 51-63.

. La crisis de la pintura de caballete. In: La pintura moderna y otros ensayos. Madrid: Siruela. 2006c. p. 45-50. 1999.

. Homemade esthetics: observations on art and Taste. Oxford: University Press,

Rumo a mais um novo Laocoonte. In: FERREIRA, G.; MELLO, C. C. (org.). Clement Greenberg e o debate crítico. Rio de Janeiro: Jorge Zahar, 1997a. p. 45-59.

. Pintura modernista. In: FERREIRA, G.; MELLO, C. C. (org.). Clement Greenberg e o debate critico. Rio de Janeiro: Jorge Zahar, 1997b. p. 101-110.

. Arte abstrata. In: FERREIRA, G.; MELLO, C. C. (org.). Clement Greenberg e o debate crítico. Rio de Janeiro: Jorge Zahar, 1997c. p. 61-66.

. Pintura "à americana". In: FERREIRA, G.; MELLO, C. C. (org.). Clement Greenberg e o debate critico. Rio de Janeiro: Jorge Zahar, 1997d. p. 75-94.

. Queixas de um crítico de arte. In: FERREIRA, G.; MELLO, C. C. (org.). Clement Greenberg e o debate critico. Rio de Janeiro: Jorge Zahar, 1997e. p. 117-124.

. Abstração pós-pictórica. In: FERREIRA, G.; MELLO, C. C. (org.). Clement Greenberg e o debate crítico. Rio de Janeiro: Jorge Zahar, 1997f. p. 111-116.

. The present prospect of american painting and sculpture. In: O'BRIAN, J. (Org.). Clement Greenberg: Collected Essays and Criticism, v. 2. Chicago: The University of Chicago Press, 1986.

HEIDEGGER, M. El origen de la obra de arte. In: Arte y poesía. Buenos Aires: Fondo de Cultura Económica, 2014.

KANT, I. Crítica del discernimiento. Edición y traducción de Roberto R. Aramayo y Salvador Mas. Madrid: Antonio Machado, 2003.

KRAUSS, R. Uma visão do modernismo. In: FERREIRA, G.; MELLO, C. C. (org.). Clement Greenberg e o debate crítico. Rio de Janeiro: Jorge Zahar, 1997. p. 163-174.

LASCH, C. The cultural Cold War. In: BERNSTEIN, B. J. (ed.). Towards a New Past, Dissenting Essays in American History. New York: Pantheon, 1968.

LESSING, G. E. Laocoonte ou sobre as fronteiras da pintura e da poesia. Tradução e notas de Márcio Seligmann-Silva. São Paulo: Iluminuras, 1998.

MOLES, A. El kitsch: el arte de la felicidad. Barcelona: Paidós, 1990.

NEWMAN, B. Resposta a Clement Greenberg. In: FERREIRA, G.; MELLO, C. C. (org.). Clement Greenberg e o debate critico. Rio de Janeiro: Jorge Zahar, 1997. p. 151-154.

PASSOS, Ú. O juízo estético em Greenberg. Artefilosofia, Ouro Preto, n. 15, p. 46-58, dez. 2013. 
RAUSCHENBERG, N. Entre la serigrafía y el cine. Para una biografía sociológica de Andy Warhol. Revista Tempo Social, USP, v. 31, n. 1, p. 301-321, 2019.

ROSENBERG, H. Action painting: crise e distorçóes. In: FERREIRA, G.; MELLO, C. C. (org.) Clement Greenberg e o debate critico. Rio de Janeiro: Jorge Zahar, 1997. p. 155-162. . The tradition of the new. New York: Perseus Group Books, 1994.

SHAPIRO, D.; SHAPIRO, C. Abstract expressionism: the politics of a apolitical painting. In: FRASCINA, F. (org.) Pollock and After. London and New York: Routledge, 1985. 